\title{
Mastoid and Opisthion-Bimastoid Triangles for Sex Determination in a Brazilian Sample
}

\author{
Triangulos Mastoideo y Opistión-Bimastoideo para la \\ Determinación del Sexo en una Muestra Brasileña
}

\begin{abstract}
Silvana Regina Prado Penteado de Castro ${ }^{1}$; Juliana Haddad ${ }^{1}$; Alexandre Rodrigues Freire ${ }^{1}$; Olavo Barbosa de Oliveira Neto²; Felippe Bevilacqua Prado ${ }^{1}$; Ana Cláudia Rossi ${ }^{1}$ \& Fausto Bérzin ${ }^{1}$
\end{abstract}

DE CASTRO, S. R. P. P.; HADDAD, J.; FREIRE, A. R.; NETO, O. B. O.; PRADO, F. B.; ROSSI, A. C. \& BÉRZIN, F. Mastoid and opisthion-bimastoid triangles for sex determination in a Brazilian sample. Int. J. Morphol., 39(4):1068-1073, 2021.

SUMMARY: Human identification involving mutilation, advanced decomposition, and skeletonized materials is a challenge for professionals in forensic medicine and dentistry. This study was aimed at a morphometric analysis of the mastoid and bimastoid triangles to determine sex in a Brazilian population. The sample included 80 human skulls ( 34 females and 46 males; age: 18 to 60 years) from individuals with death certificates. Linear measurements $(\mathrm{mm})$ of the mastoid process — right $(\mathrm{n}=3)$ and left $(\mathrm{n}=3)$ - and the opisthionbimastoid $(n=3)$ triangles were taken (digital caliper) by two previously trained researchers. Three cranial points — asterion, porion and process - were determined for the right and left mastoid triangle and three others - (1) opisthion and (2) right and (3) left mastoid — for the bimastoid triangle. Heron's formula was used to calculate the area of the triangles assessed. Data were submitted to the ShapiroWilk normality test, followed by the unpaired Student's $t$ test or the Mann-Whitney U test, depending on the data distribution verified in the normality test (GraphPad Prism 5.01; $<<0.05$ ). The ROC curve was used to measure the accuracy of the variables toward sex determination. The opisthion-bimastoid triangle showed high accuracy and significant differences in all the variables assessed and thus was considered a potential element for sex determination in the Brazilian population assessed.

KEYWORDS: Sex differences; Skull; Craniometry; Mastoid process.

\section{INTRODUCTION}

Human identification, or biological profile determination, involving body mutilation and skeletal remains is a challenge for professionals in forensic medicine and dentistry. In forensics, the biological profile is defined as the determinant of sex, age, stature, and ancestry of the deceased (Kanchan et al., 2013).

In human skeletons, sex can be determined through the morphological characteristics of the pelvis with a high level of reliability (Musilová et al., 2016). However, when the pelvis and other bones are fragmented or missing, the skull provides a reliable alternative for sex determination (Krishan et al., 2016; Bhayya et al., 2018; González-Colmenares et al., 2019; Sinhorini et al., 2019). The mastoid process of the skull has been considered useful in determining sex. Its physical and anatomical characteristics make it highly resistant to any physical damage, one of the reasons why it remains intact even in fragmented skulls (Madadin et al., 2015).
A morphometric method for sex determination has shown high sexing reliability in Brazilian dry skulls. It includes measurements from a cranial triangle (mastoid region) involving three points - porion, mastoidale and asterion (de Paiva \& Segre, 2003). Another study on sexual dimorphism using measurements of the mastoid triangle of 388 fragmented skulls in a Malaysian population reported relatively high accuracy towards sex determination (Ibrahim et al., 2018). Sinhorini et al. assessing four cranial triangles (facial, bimastoid, mastoid, and occipital) in 100 Brazilian human skulls also reported high accuracy towards sex determination and considered the four morphometric dimensions assessed as sexually dimorphic.

Anthropologically, the mastoid region, including the bimastoid triangle, has been of great relevance for sex determination using dry skulls. Therefore, the present study was aimed at sex determination using a morphometric

\footnotetext{
${ }^{1}$ Biosciences Department, Anatomy Division, School of Dentistry of Piracicaba, University of Campinas - UNICAMP, Brazil.

${ }^{2}$ Biosciences Center, Department of Anatomy, Federal University of Pernambuco -UFPE, Recife, Brazil.

Coordination for the Improvement of Higher Education Personnel (CAPES) for the financial support. Protocol number: 88882.434534/2019-01.
} 
analysis of the mastoid and bimastoid triangles in a Brazilian population. The null hypothesis is that the mastoid and bimastoid triangles in male and female skulls provide anatomical dimensions that aid in determining sex.

\section{MATERIAL AND METHOD}

This study was approved by the Research Ethics Committee (protocol number: 19080019.3.0000.5418) from Piracicaba Dental School - State University of Campinas (UNICAMP).

Sample: The sample included 80 human skulls ( 34 females and 46 males; age: 18 to 60 years), randomly chosen from the biobank (Human Bones, Teeth and Corpses) of Piracicaba Dental School, University of Campinas (UNICAMP).

Skulls having no fractures and signs of trauma or surgical interventions at its base and in the mastoid region, on both sides, were included. The measurements were carried out by two previously calibrated researchers who were blinded to the sex concerning the skulls. For the calibration, 20 skulls were used. Thirty days after calibration, the 20 skulls were re-assessed by the same researchers to verify the intra- and inter-examiner reliability.

Protocol of measurements. Based on a previous protocol by Sinhorini et al., linear measurements $(\mathrm{mm})$ of the right $(n=3)$ and left $(n=3)$ mastoid and the opisthion-bimastoid $(n=3)$ triangles were taken with a $150-\mathrm{mm}$-range digital caliper with an accuracy of $\pm 0.03 \mathrm{~mm}$ (King Tools, Suzhou, China). The median sagittal and the Frankfurt planes were used as references to standardize the measurements.

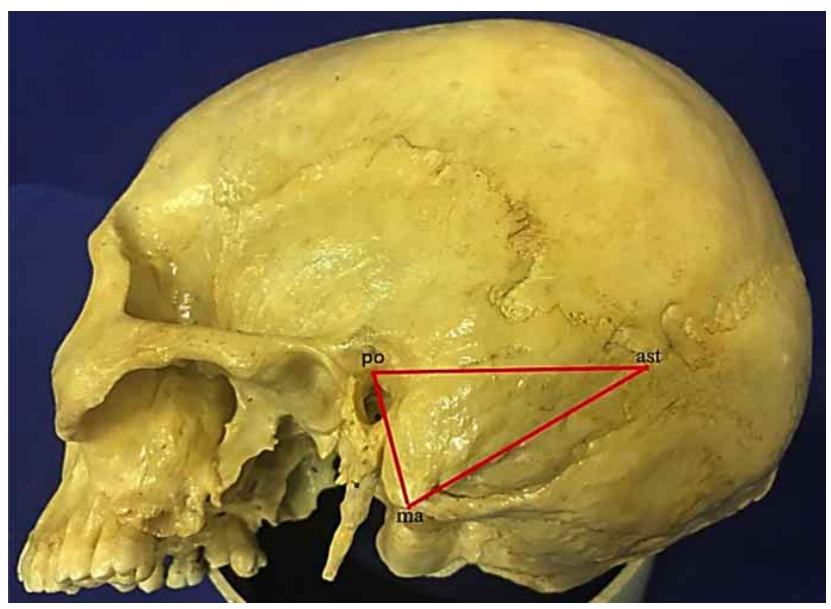

Fig. 1. The mastoid triangle on the left side of the skull and the linear measurement points: asterion (ast), porion (po) and mastoidale (ma).
The mastoid triangle, on both sides of the skull, included three reference points - asterion (ast), porion (po) and mastoidale (ma). The measurements were taken considering three linear distances - ast-po (side 1), ast-ma (side 2) and po-ma (side 3) (Fig. 1).

The bimastoid triangle was based on three reference points - the opisthion (op) and the left and right mastoidales (ma). The measurements were taken considering three linear distances - op to left ma (side 1), op to right ma (side 2), and right to left ma (side 3) (Fig. 2).

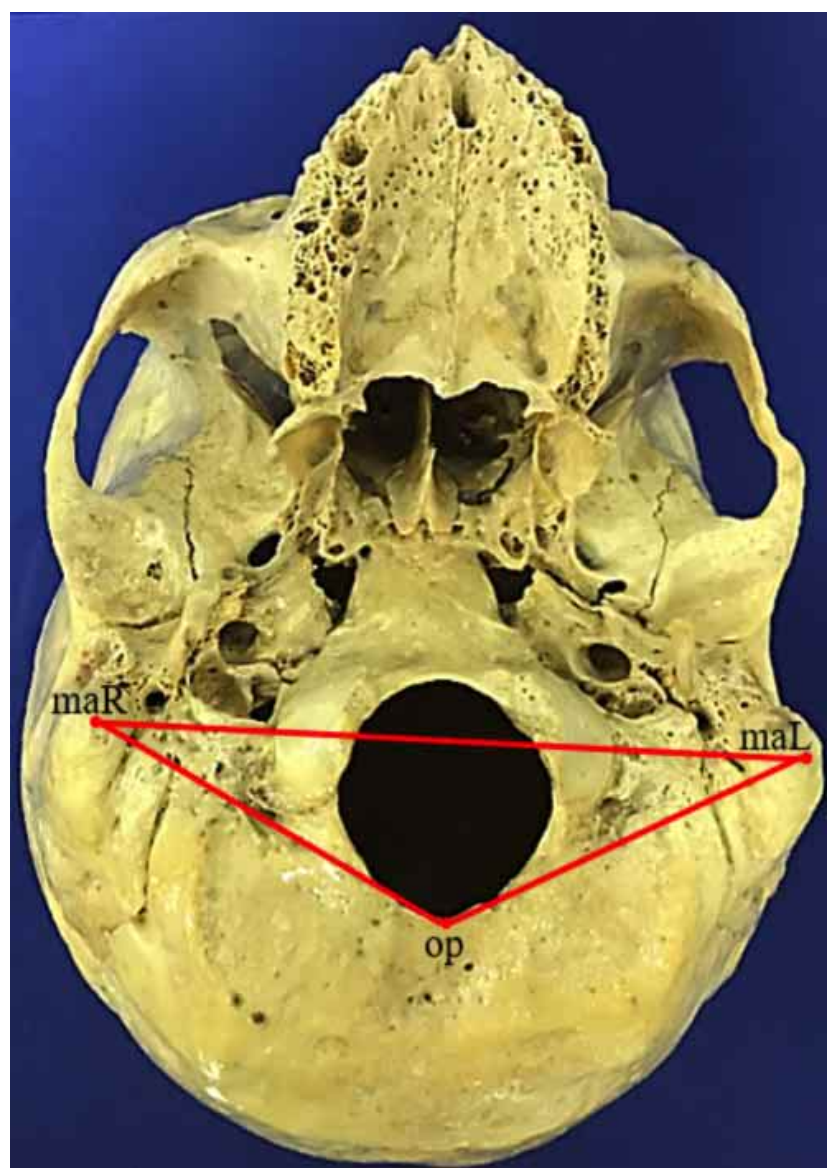

Fig. 2. The opisthion-bimastoid triangle (inferior view of the skull) and linear measurement points: opisthion (op) and left (maL) and right (maR) mastoidales.

Initially, the perimeters and areas of the triangles were calculated. The perimeters of the triangles were determined by summing the sides of the mastoid (ast-po + ast-ma + poma) and those of the opisthion-bimastoid (op-maL +op-maR + maL-maR). The areas of the triangles were calculated using the Heron's formula (Kemkes \& Göbel, 2006) and expressed in square millimeters $\left(\mathrm{mm}^{2}\right)$ : 
Mastoid triangle area $=$

$\sqrt{((\text { perimeter } / 2) x(\text { perimeter } / 2-\text { ast }- \text { po }) x(\text { perimeter } / 2-\text { ast }- \text { ma }) x(\text { perimeter } / 2-p o-m a))}$

Opisthion-bimastoid triangle area=

$\sqrt{((\text { perimeter } / 2) x(\text { perimeter } / 2-\text { op }- \text { maR }) x(\text { perimeter } / 2-\text { op }- \text { maL }) x(\text { perimeter } / 2-m a R-m a L)}$

The intraclass correlation coefficient (ICC) was calculated to determine the level of agreement between the examiners. The Shapiro-Wilk normality test was carried out, followed by the unpaired Student's t-test or the Mann-Whitney U test, depending on the distribution of the data verified in the normality test. The left and right sides (mastoid triangle) of the same-sex individuals and the same side of different-sex individuals were compared. The receiver operating characteristic (ROC) curve was used to classify the accuracy of the measurements used to determine sex, where the greater the AUC, the greater is the potential of the variable in determining sex (Figs. 5 and 6).

Correlation coefficient ( $\mathrm{r}$ ), followed by regression analysis, was used to verify correlation between the variables of the mastoid and the opisthion-bimastoid triangles at a significance level of $5 \%(\mathrm{p}<0.05)$ using the GraphPad Prism 5.01 software (GraphPad, San Diego, USA).

\section{RESULTS}

Table I shows the mean values for the perimeter and area and for the three sides (astpo, ast-ma, and po-ma) of the mastoid triangle on both sides (right and left) of the skull males and females. No statistically significant difference was observed among the variables assessed.
Figure 3 illustrates a comparison of the mastoid triangle variables concerning males and females, considering the same side of the skulls. The values concerning the po-ma variable (a) and the perimeter and the area (b) of the right mastoid triangle were significantly greater for males $(p<0.05)$.

Figure 4 illustrates a graph with a comparison between males and females considering the opisthion-bimastoid triangle: variable distances (a), perimeter (b) and area (b). All variables assessed showed significantly higher values for males $(\mathrm{p}<0.05)$.

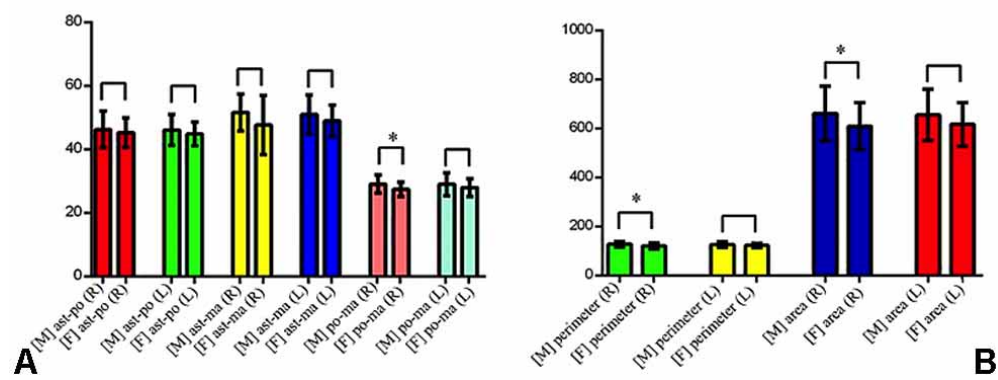

Fig. 3. Comparative illustration of the mastoid triangle variables, considering the same side of the skull for males and females. $*$ = significant difference $(\mathrm{p}<0.05)$; ast-po $=$ asterion-porion distance; ast-ma $=$ asterion-mastoid distance; po-ma $=$ porion-mastoid distance; $\mathrm{M}=$ male; $\mathrm{F}=$ female; $\mathrm{R}=$ right side; $\mathrm{L}=$ left side.
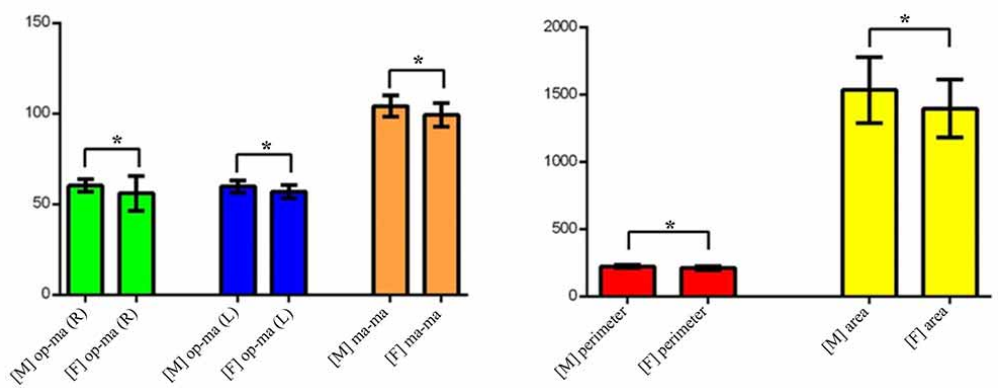

Fig. 4. Comparative illustration of the opisthion-bimastoid triangle variables between males and females. $*=$ significant difference $(\mathrm{p}<0.05)$; op-maR $=$ opisthion-mastoid distance; op-maL = opisthion-mastoid distance; $\mathrm{maR}-\mathrm{maL}=$ mastoid-mastoid distance (bimastoid) $\mathrm{M}=$ male sex; $\mathrm{F}=$ female sex; $\mathrm{R}=$ right side; $\mathrm{L}=$ left side.

Table I. Mean values and standard deviation for the three sides (ast-po, ast-ma, and po-ma) and perimeter and area of the mastoid triangle (right and left sides) for males and females; ast-po = asterion-porion distance; ast-ma = asterion-mastoid distance; po-ma = porionmastoid distance.

\begin{tabular}{|c|c|c|c|c|c|c|c|c|c|c|c|}
\hline & \multicolumn{5}{|c|}{ Male $(n=46)$} & \multicolumn{5}{|c|}{ Female $(n=34)$} \\
\hline & & ast-po & ast-ma & po-ma & perimeter & area & ast-po & ast-ma & po-ma & perimeter & area \\
\hline $\begin{array}{l}\text { Right } \\
\text { side }\end{array}$ & $\begin{array}{c}\text { Mean value } \\
\text { (+/-Standard } \\
\text { deviation) }\end{array}$ & $\begin{array}{c}46.25 \\
(+/-5.785)\end{array}$ & $\begin{array}{c}51.58 \\
(+/-5.818)\end{array}$ & $\begin{array}{c}29.06 \\
(+/-2.862)\end{array}$ & $\begin{array}{c}126.9 \\
(+/-11.72)\end{array}$ & $\begin{array}{c}661.0 \\
(+-111.9)\end{array}$ & $\begin{array}{c}45.23 \\
(+/-4.675)\end{array}$ & $\begin{array}{c}47.72 \\
(+-9.330)\end{array}$ & $\begin{array}{c}27.40 \\
(+/-2.310)\end{array}$ & $\begin{array}{c}120.3 \\
(+/-12.89)\end{array}$ & $\begin{array}{c}609.5 \\
(+/-95.59)\end{array}$ \\
\hline $\begin{array}{l}\text { Left } \\
\text { side }\end{array}$ & $\begin{array}{l}\text { Mean value } \\
\text { (+/- Standard } \\
\text { deviation) }\end{array}$ & $\begin{array}{c}46.12 \\
(+/-4.829)\end{array}$ & $\begin{array}{c}50.97 \\
(+/-6.191)\end{array}$ & $\begin{array}{c}29.02 \\
(+/-3.569)\end{array}$ & $\begin{array}{c}126.1 \\
(+/-11.18)\end{array}$ & $\begin{array}{c}655.5 \\
(+/-105.0)\end{array}$ & $\begin{array}{c}44.83 \\
(+/-3.733)\end{array}$ & $\begin{array}{c}49.00 \\
(+/-4.882)\end{array}$ & $\begin{array}{c}27.95 \\
(+/-2.823)\end{array}$ & $\begin{array}{c}121.8 \\
(+/-9.524)\end{array}$ & $\begin{array}{c}616.7 \\
(+/-89.75)\end{array}$ \\
\hline & p-value & 0.4828 & 0.7931 & 0.9493 & 0.7663 & 0.5197 & 0.7017 & 0.7769 & 0.3850 & 0.6009 & 0.7487 \\
\hline
\end{tabular}


Table II shows the confidence interval and the mean values for the area under the ROC Curve (AUC) concerning the perimeter and area and the three sides (ast-po, ast-ma, and po-ma) of the mastoid triangle on both sides (right and left) of the skull. The higher the AUC value, the greater the potential of the variables in determining sex. Significant difference was observed for po-ma, perimeter, and area on the right side.

Figures 5 and 6 illustrate graphs of the area under the ROC Curve (AUC) concerning the three sides and the perimeter and area, respectively, of the opisthion-bimastoid triangle. All variables assessed showed statistically significant differences.

Table III shows data concerning the regression analysis and confidence interval for the mastoid triangle. Significant difference was observed for most variables (poma, perimeter, and area) on the right side.

Table IV shows data regarding the regression analysis and confidence interval for the opisthion-bimastoid triangle. Significant difference was observed for all the variables assessed.

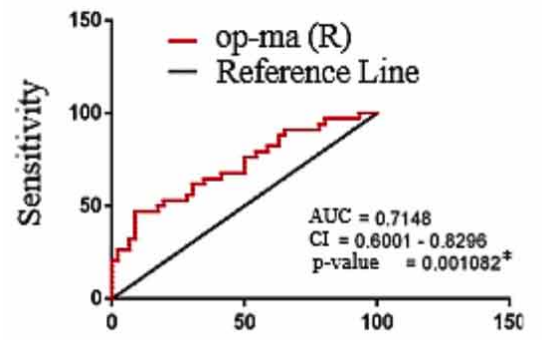

A

Specificity

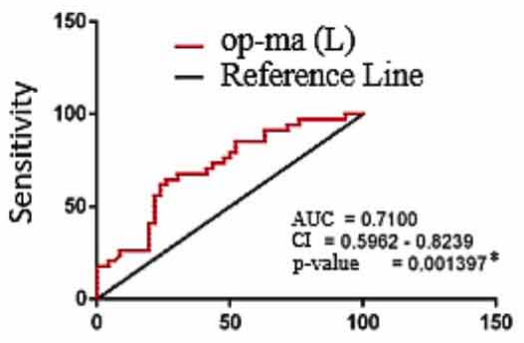

Specificity

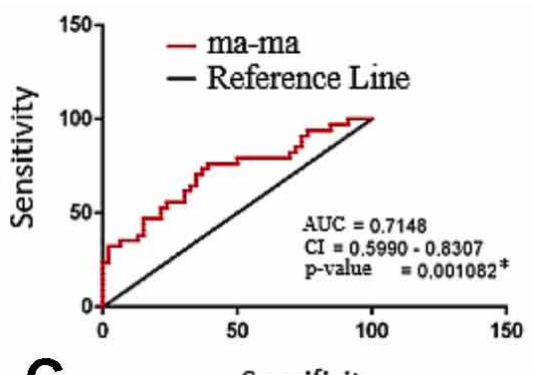

C

Specificity

Fig. 5. AUC = area under the ROC Curve; $*$ = significant difference; CI = confidence interval; op-maR = opisthion-mastoid distance on the right side; op-maL= opisthion-mastoid distance on the left side; maR-maL = mastoid-mastoid distance (bimastoid).

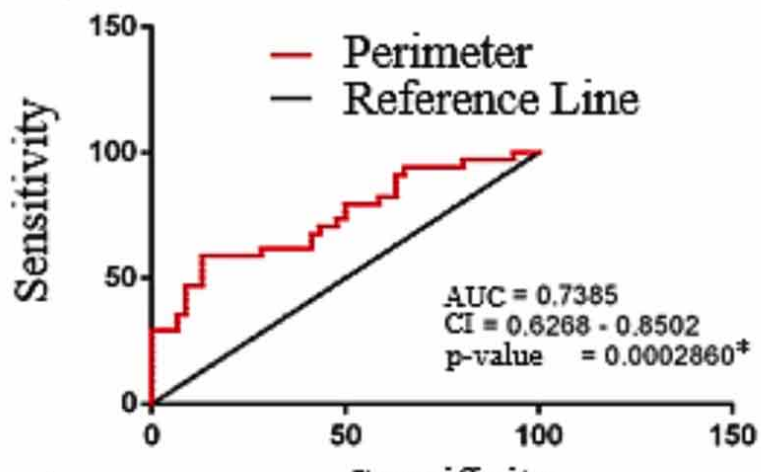

A

Specificity

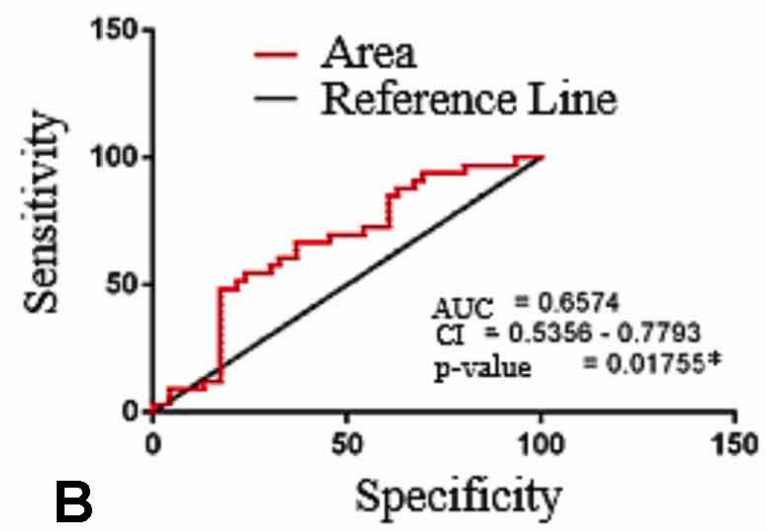

Fig. 6. AUC $=$ area under the ROC Curve. $*=$ significant difference; $\mathrm{CI}=$ confidence interval

Table II. Confidence interval and mean values for the area under the ROC Curve (AUC) for mastoid triangle's sides, perimeter and area considering both sides of the skull; ${ }^{*}=$ significant difference; $\mathrm{CI}=$ confidence interval; ast-po $=$ asterion-porion distance; ast-ma $=$ asterion-mastoid distance; po-ma = porion-mastoid distance.

\begin{tabular}{lcccccc}
\hline & \multicolumn{3}{c}{ Right side } & \multicolumn{2}{c}{ Left side } \\
\hline Measurement & AUC & CI & p-value & AUC & CI & p-value \\
\hline ast-po & 0.5671 & $0.4393-0.6949$ & 0.3069 & 0.5764 & $0.4492-0.7036$ & 0.2449 \\
ast-ma & 0.6279 & $0.5020-0.7537$ & 0.05165 & 0.5818 & $0.4560-0.7077$ & 0.2129 \\
po-ma & 0.6841 & $0.5674-0.8009$ & $0.005083^{*}$ & 0.5793 & $0.4540-0.7045$ & 0.2275 \\
perimeter & 0.6317 & $0.5078-0.7557$ & $0.04503^{*}$ & 0.5815 & $0.4554-0.7076$ & 0.2147 \\
area & 0.6357 & $0.5124-0.7590$ & $0.04064^{*}$ & 0.5793 & $0.4531-0.7055$ & 0.2275 \\
\hline
\end{tabular}


Table III. Regression analysis and confidence interval data for the mastoid triangle variables considering both sides; * $=$ significant difference; $\mathrm{r}=$ correlation coefficient $\mathrm{CI}=$ confidence interval; ast-po = asterion-porion distance; ast-ma = asterion-mastoid distance; po-ma = porion-mastoid distance.

\begin{tabular}{|c|c|c|c|c|c|c|c|c|c|c|}
\hline & \multicolumn{5}{|c|}{ Right side } & \multicolumn{5}{|c|}{ Left side } \\
\hline & ast-po & ast-ma & po-ma & perimeter & area & ast-po & ast-ma & po-ma & perimeter & area \\
\hline $\mathrm{r}$ & -0.1150 & -0.2190 & -0.3154 & -0.2256 & -0.2319 & -0.1309 & -0.1402 & -0.1358 & -0.1396 & -0.1358 \\
\hline$r^{2}$ & 0.009193 & 0.06231 & 0.08945 & 0.06709 & 0.05627 & 0.02114 & 0.02945 & 0.02580 & 0.04070 & 0.03706 \\
\hline \multirow[t]{2}{*}{ CI } & -0.3324 & -0.4241 & -0.5054 & -0.4297 & -0.4363 & -0.3466 & -0.3550 & -0.3511 & -0.3545 & -0.3511 \\
\hline & to 0.1140 & to 0.007407 & to -0.09618 & to 0.0004992 & to -0.004629 & to 0.09809 & to 0.08869 & to 0.09312 & to 0.08925 & to 0.09312 \\
\hline p-value & 0.3098 & 0.0510 & $0.0044 *$ & $0.0442 *$ & $0.0398 *$ & 0.2473 & 0.2150 & 0.2298 & 0.2168 & 0.2298 \\
\hline
\end{tabular}

Table IV. Regression analysis and confidence interval data for the opisthion-bimastoid triangle variables; $*=$ significant difference; $r=$ correlation coefficient; $\mathrm{CI}=$ confidence interval; op-maR = opisthion-mastoid distance on the right side; op-maL $=$ opisthion-mastoid distance on the left side; ma-ma = mastoid-mastoid distance (Bimastoid).

\begin{tabular}{lccccc}
\hline & op-maR & op-maL & maR-maL & perimeter & area \\
\hline $\mathrm{r}$ & -0.3679 & -0.3597 & -0.3679 & -0.4084 & -0.2690 \\
$\mathrm{r}^{2}$ & 0.09274 & 0.1403 & 0.1353 & 0.1826 & 0.07993 \\
$\mathrm{CI}$ & -0.5484 to -0.1547 & -0.5417 to 0.1455 & -0.5484 to- 0.1547 & -0.5809 to -0.2009 & -0.4679 to- 0.04423 \\
$\mathrm{p}$-value & $0.0008^{*}$ & $0.0010^{*}$ & $0.0008^{*}$ & $0.0002^{*}$ & $0.0165^{*}$ \\
\hline
\end{tabular}

\section{DISCUSSION}

Few are the pre-established metric and morphological parameters to determine sex in Brazilians for forensic purposes (Kramer et al., 2018). Validating reliable methodologies in different populations is essential to improve anthropological techniques for human identification (Sinhorini et al.). Therefore, the present study aimed at determining sex in Brazilian skulls considering specific morphometric characteristics of the mastoid and bimastoid triangles.

The mastoid triangle showed significant difference between males and females (higher mean values for men) for most variables (po-ma, perimeter, and area) on the right side of the skull, with the po-ma being the most accurate $(68.41 \%)$, followed by the area $(63.57 \%)$ and perimeter $(63.17 \%)$. The difference in size between males and females might be due to the variation in the growth of the mastoid process, in both males and females (Yilmaz et al., 2015; Bhayya et al.). In a Saudi population (206 skull CT images), the three sides of the mastoid triangle were considered sexually dimorphic, with the porionmastoid distance being reported as the best parameter to determine sex, followed by the area of the mastoid triangle, with an accuracy of $69.4 \%$ and $68.4 \%$, respectively (Madadin et al., 2015).

The opisthion-bimastoid triangle showed significant difference between males and females in all the variables assessed (Table IV). Based on the ROC curve analysis (Figs. 5 and 6), the opisthion-bimastoid triangle, when compared with the mastoid triangle, was significantly more dimorphic and more accurate (op-maR $=71.48 \%$; op-maL $=71.00 \%$; maL-maR $=71.48 \%$; perimeter $=73.85 \%$; area $=65.74 \%$ ). In an Indian population (100 dry skulls), all the opisthion-bimastoid variables (distances and area) assessed for sex determination showed higher mean values for males, with $75 \%$ of the skulls showing greater significant difference for the maR-maL distance, followed by the other distances and area $(70 \%)$ of the opisthion-bimastoid (Deepali et al., 2013).

Four cranial triangles - facial, bimastoid, mastoid, and occipital - were used to determine sex in a Brazilian population, considering all the triangles assessed as potential predictors, with the bimastoid triangle showing an accuracy of $71.4 \%$ (Sinhorini et al.) Therefore, the present study was aimed at a morphometric analysis of the mastoid and bimastoid triangles to determine sex in a Brazilian population. Further studies are needed to verify our findings, considering different populations and laterality differences concerning the mastoid triangle.

In conclusion, the morphometric parameters of the mastoid and opisthion-bimastoid triangles were sexually dimorphic. The mastoid triangle, on the right side, showed significant differences only in the porionmastoid distance, perimeter and area, while the opisthionbimastoid triangle showed high accuracy and significant differences in all variables assessed; accordingly, it holds potential parameters for sex determination in the Brazilian population assessed. 
DE CASTRO, S. R. P. P.; HADDAD, J.; FREIRE, A. R.; NETO, O. B. O.; PRADO, F. B.; ROSSI, A. C. \& BÉRZIN, F. Triángulos mastoideo y opistion-bimastoideo para la determinación del sexo en una muestra brasileña. Int. J. Morphol., 39(4):1068-1073, 2021.

RESUMEN: La identificación humana que comprende la mutilación, descomposición avanzada y materiales esqueletizados, es un desafío para los profesionales de la medicina forense y de la odontología. Este estudio tuvo como objetivo un análisis morfométrico de los triángulos mastoideo y bimastoideo para determinar el sexo en una población brasileña. La muestra incluyó 80 cráneos humanos ( 34 mujeres y 46 hombres; edad: 18 a 60 años) de sujetos con certificado de defunción. Se tomaron las medidas lineales $(\mathrm{mm})$ del proceso mastoides - derecha $(\mathrm{n}=3)$ e izquierda $(\mathrm{n}=3)$ - y los triángulos opistion-bimastoide $(\mathrm{n}=3)$ (caliper digital) por dos investigadores previamente entrenados. Se determinaron tres puntos craneales - asterion, porion y proceso mastoides - para el triángulo mastoideo derecho e izquierdo y otros tres - (1) opistion y (2) proceso mastoides derecho e izquierdo - para el triángulo bimastoideo. Se utilizó la fórmula de Heron para calcular el área de los triángulos evaluados. Los datos se analizaron con la prueba de normalidad de Shapiro-Wilk, seguida de la prueba t de Student para datos no apareados o la prueba U de Mann-Whitney, según la distribución de datos verificada en la prueba de normalidad (GraphPad Prism 5.01; p <0.05). La curva ROC se utilizó para medir la precisión de las variables hacia la determinación del sexo. El triángulo opistion-bimastoide mostró una alta precisión y diferencias significativas en todas las variables evaluadas, por lo que se consideró un elemento probable para la determinación del sexo en la población brasileña evaluada.

PALABRAS ClaVE: Diferencias de sexo; Cráneo; Craneometría; Proceso mastoides.

\section{REFERENCES}

Bhayya, H.; Avinash Tejasvi, M. L.; Jayalakshmi, B. \& Reddy, M. Craniometric assessment of gender using mastoid process. J. Indian Acad. Oral Med. Rad., 30:52-7, 2018.

de Paiva, L. A. S. \& Segre, M. Sexing the human skull through the mastoid process. Rev. Hosp. Clin. Fac. Med. Sao Paulo, 58(1):15-20, 2003.

Deepali, J.; Jasuja, O. P. \& Nath, S. Sex determination of human crania using Mastoid triangle and Opisthion-Bimastoid triangle. J. Forensic Leg. Med., 20(4):255-9, 2013.

González-Colmenares, G.; Sanabria Medina, C.; Rojas-Sánchez, M. P.; León, K. \& Malpud, A. Sex estimation from skull base radiographs in a contemporary Colombian population. J. Forensic Leg. Med., 62:7781, 2019.

Ibrahim, A.; Alias, A.; Shafie, M. S.; Das, S. \& Mohd Nor, F. Osteometric estimation of sex from mastoid triangle in malaysian population. Asian J. Pharm. Clin. Res., 11:303-7, 2018.

Kanchan, T.; Gupta, A. \& Krishan, K. Estimation of sex from mastoid triangle - A craniometric analysis. J. Forensic Leg. Med., 20(7):85560, 2013.

Kemkes, A. \& Göbel, T. Metric assessment of the "mastoid triangle" for sex determination: a validation study. J. Forensic Sci., 51(5):985-9, 2006.
Kramer, N. A.; Lopez-Capp, T. T.; Michel-Crosato, E. \& Biazevic, M. G. H. Sex estimation from the mastoid process using Micro-CT among Brazilians: Discriminant analysis and ROC curve analysis. J. Forensic Radiol. Imaging, 14:1-7, 2018.

Krishan, K.; Chatterjee, P. M.; Kanchan, T.; Kaur, S.; Baryah, N. \& Singh, R. K. A review of sex estimation techniques during examination of skeletal remains in forensic anthropology casework. Forensic Sci. Int., 261:165.e1-8, 2016.

Madadin, M.; Menezes, R. G.; Al Dhafeeri, O.; Kharoshah, M. A.; Al Ibrahim, R.; Nagesh, K. R. \& Ramadan, S. U. Evaluation of the mastoid triangle for determining sexual dimorphism: A Saudi population-based study. Forensic Sci. Int., 254:244.e1-4, 2015.

Musilová, B.; Dupej, J.; Velemínská, J.; Chaumoitre, K. \& Bruzek, J. Exocranial surfaces for sex assessment of the human cranium. Forensic Sci. Int., 269:70-7, 2016.

Sinhorini, P. A.; Costa, I. A. P.; Lopez-Capp, T. T.; Biazevic, M. G. H. \& de Paiva, L. A. S. Comparative analysis of four morphometric methods for sex determination: A study conducted on human skulls. Leg. Med. (Tokyo), 39:29-34, 2019.

Yilmaz, M. T.; Yüzbasioglu, N.; Cicekcibasi, A. E.; Seker, M. \& Sakarya, M. E. The evaluation of morphometry of the mastoid process using multidetector computed tomography in a living population. J. Craniofac. Surg., 26(1):259-63, 2015.

\section{Corresponding author:}

Silvana Regina Prado Penteado de Castro

Department of Biosciences

Anatomy Division

School of Dentistry of Piracicaba

University of Campinas

UNICAMP

901 Limeira Avenue

Areião13414-903

Piracicaba, SP.

BRAZIL

\section{E-mail: silcastro1709@gmail.com}

Received: 04-04-2021

Accepted: 09-05-2021 